\section{An easier impression}

With the digital revolution in full swing, digital dental impressions have become commonplace in the practice.

Practitioners can stay ahead of the curve with the True Definition scanner from 3M Oral Care. This device is small and easy to use and, thanks to its innovative and stateof-the-art design, effectively minimises distortion and error. This is essential for accurate impressions and makes the
True Definition ideal for a wide variety of different indications.

The True Definition scanner is changing the way practitioners are taking impressions in the practice. To find out more, contact the expert 3M Oral Care team today.

For more information, call 0845602 5094 or visit www.3Mespe.co.uk.

$3 \mathrm{M}$ and True Definition are trademarks of the $3 \mathrm{M}$ Company.

\title{
Keeping it simple for the New Year
}

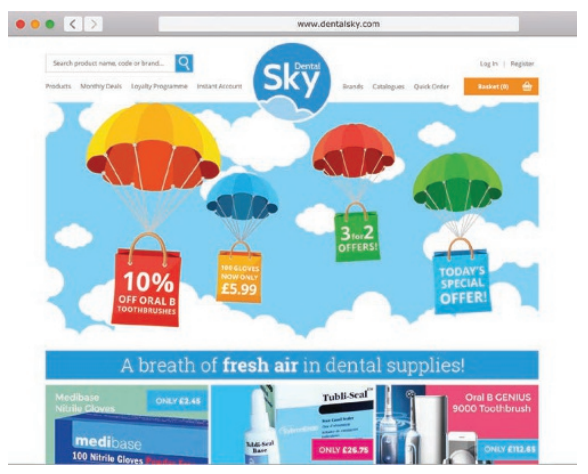

Work can be complicated, but one thing that shouldn't be is ordering your sundries. Dental Sky doesn't believe in confusing promotions or reams of small print. Like a well-known retailer they will never knowingly be undersold and believe in price clarity and simple offers so you know exactly what you're getting and at what price.

The company, partly owned by a self-confessed IT geek, has recently overhauled its website so that the design and layout of the site is even easier to navigate. All customers

ordering online automatically receive a $2 \%$ discount; a further $2 \%$ discount is given for upfront payments. There are several payment options - you can order with your American Express card (if you're collecting Airmiles) or you may prefer the simplicity of PayPal. Some customers even choose to use their Amazon account.

Dental Sky also runs a simple loyalty programme that will reward all customers, whatever the size of their practice. For every $£ 1$ spent you earn one Loyalty Point. Within no time even the smallest of practices will have accrued enough points to cash in on some amazing rewards. Chocolates are welcome within most staff rooms (excellent plaque control is a taken!) so there are a number of sweet offerings once you reach 300 points (ie once you've spent $\mathfrak{£} 300$ in total) such as a Cadbury Treasure Box. If you don't have a Dental Sky account you can open one today: no credit checks, no paperwork and no hassle! Just pop online to register and you're ready to go. Visit www.dentalsky.com.

\section{Next generation CAD/CAM}

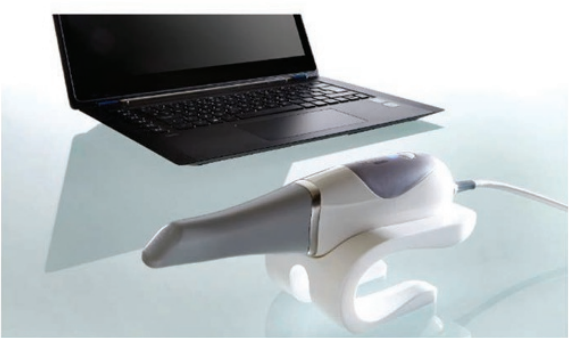

Representing the latest generation CAD/ CAM intraoral scanner from Carestream Dental, the CS 3600 acquires highly accurate images quickly and easily.

Indicated for use in restorative, orthodontic and implant-borne restorative dentistry, the innovative scanner features high speed continuous scanning for a smooth and simple workflow. With its intelligent matching system it also enables you to freely complete any missing data at any time, while its scan check history allows you to go backward during the live scanning process for an even more refined digital impression.

What's more, the intuitive CS 3600 is easy to use and produces precise HD 3D colour images for superb quality and enhanced diagnostics and treatment planning.

Alongside the cutting-edge technology, you can also use ongoing support from the knowledgeable customer service team at Carestream Dental, helping you truly maximise your investment.

For more information on how the CS 3600 could improve your clinical dentistry and make your life easier, contact Carestream Dental today on 08001699692 or visit www. carestreamdental.co.uk.

\section{Taking care of everything education}

Henry Schein Dental understands the pressures that dental professionals face trying to keep up-to-date with their CPD obligations. Henry Schein's Education website (hsdeducation.co.uk) provides innovative, practical resources and training courses to help dental professionals fulfil all their training and educational needs.

Covering everything, from new techniques, materials and technology to innovative practice solutions and business know-how, the site includes full details of all Henry Schein Dental's latest CPD courses which cover a host of disciplines including decontamination, orthodontics, lasers, marketing and digital dentistry.

The site also provides direct access to the Connect Dental Campus (connectdentalcampus.co.uk), an online resource featuring a vast amount of on-demand webinars, product videos and articles covering everything clinicians and technicians need to know to get ahead in the world of digital dentistry.

Henry Schein Dental Education is fully compliant with the British Dental Industry
Association's CPD Code of Practice. This Code certifies the quality and independence of the education being offered to dental professionals. So whether it's surgical or implant dentistry, digital or laser technology or if you want to ensure your team is up-to-date with HTM 01-05, Henry Schein Dental Education is the perfect accompaniment for improving $\mathrm{CPD}$ and training for you and your team.

Register for free today; visit hsdeducation.co.uk or call 01634878750 for more information. 